\title{
Respostas de Plantas de Eleusine indica sob Diferentes CONdições HídRICAS A HeRBICIdAs INIBIDORES DA ACCASE ${ }^{1}$
}

\author{
Responses of Eleusine indica Plants under Different Water Conditions to ACCase-Inhibiting \\ Herbicides
}

PEREIRA, M.R.R. ${ }^{2}$, SOUZA, G.S.F. ${ }^{3}$, MARTINS, D. ${ }^{4}$, MELHORANÇA FILHO, A.L. ${ }^{5}$ e KLAR, A.E. ${ }^{6}$

\begin{abstract}
RESUMO - Objetivou-se neste estudo avaliar a eficiência de controle de herbicidas inibidores da ACCase aplicados em pós-emergência em plantas de Eleusine indica submetidas a diferentes teores de água no solo. Os experimentos foram conduzidos em casa de vegetação, com a aplicação de três diferentes herbicidas (fluazifop-p-butil, haloxyfop-methyl e sethoxydim + óleo mineral Assist); o delineamento experimental utilizado para cada herbicida foi inteiramente casualizado, com quatro repetições, constituído de um fatorial $3 \times 4$, sendo a combinação de três manejos hídricos (-0,03, -0,07 e -1,5 MPa) e quatro doses desses produtos (100, 50, 25 e 0\% da dose recomendada). Os parâmetros fisiológicos avaliados foram: taxa fotossintética, condutância estomática, transpiração, temperatura da folha e matéria seca das plantas. As avaliações visuais de fitotoxicidade foram realizadas aos 14 dias após a aplicação. Os manejos hídricos aplicados não influenciaram o controle das plantas nos tratamentos testados, com exceção do herbicida sethoxydim, que teve sua eficiência hídrica prejudicada quando da deficiência hídrica nas aplicações das doses fracionadas. A taxa fotossintética, a transpiração e a condutância estomática foram maiores em plantas submetidas ao manejo hídrico de $13 \%$, as quais apresentaram as menores temperaturas foliares em relação à temperatura ambiente.
\end{abstract}

Palavras-chave: capim-pé-de-galinha, controle químico, restrição hídrica, planta daninha

\begin{abstract}
The objective of this study to evaluate the control efficiency of ACCase -inhibiting herbicides applied during post-emergence on plants of Eleusine indica under different soil water contents. The experiments were conducted in a greenhouse, with the application of three different herbicides (fluazifop-p-butyl, haloxyfop-methyl and sethoxydim + oil Assist) Each herbicide experiment was arranged in a completely randomized design with four replications, consisting of a $3 \times 4$ factorial scheme, with the water management strategy combinations (-0.03, -0.07 and $-1.5 \mathrm{MPa})$ and four doses of these products (100,50, 25 and $0 \%$ of the recommended dose). The physiological parameters were: photosynthetic rate, stomatal conductance, transpiration, leaf temperature and plant dry weight. Visual assessments of plant toxicity were performed at 14 days after application. Water management did not influence plant control in the treatments tested, except for sethoxydim, which had its water efficiency affected as water deficiency occurred during the application of fractionated doses. Photosynthetic rate, transpiration, and stomatal conductance were higher in plants submitted to water management of $13 \%$, also showing the lowest leaftemperatures in relation to ambient temperature.
\end{abstract}

Keywords: goosegrass, chemical control, water restriction, weed.

1 Recebido para publicação em 22.7.2010 e na forma revisada em 6.5.2011.

2 Doutora em Agronomia, Pós-Doutoranda, Faculdade de Ciências Agronômicas, Universidade Estadual Paulista "Júlio de Mesquita Filho" - FCA/UNESP, Caixa Postal 237, 18603-970 Botucatu-SP, <mariarenata10@hotmail.com>; ${ }^{3}$ Engo-o Agr ${ }^{\circ}$., M.Sc, Doutorando, Faculdade de Ciências Agrárias, Universidade Estadual Paulista - FCA/UNESP, Botucatu-SP, ${ }^{4}$ Professor Adjunto, Dep. de Produção Vegetal, FCA/UNESP, Botucatu-SP, ${ }^{5}$ Professor Adjunto, Universidade Federal do Acre - UFA, Cruzeiro do Sul-AC; ${ }^{6}$ Professor Titular, Dep. de Engenharia Rural, FCA/UNESP, Botucatu-SP.

Planta Daninha, Viçosa-MG, v. 29, n. 2, p. 397-404, 2011 


\section{INTRODUÇÃO}

As interferências das plantas daninhas nas culturas agrícolas podem ocorrer por competição por recursos necessários ao seu crescimento, como água, luz e nutrientes, e também pela alelopatia.

As plantas atualmente cultivadas passaram por vários processos de melhoramento, visando quase sempre à maior produtividade; dessa forma, acabam sofrendo mais com os efeitos da competição (Fontes, 2003), principalmente quando têm a interferência de plantas fotossinteticamente eficientes (C4), como a espécie Eleusine indica, popularmente conhecida como capim-pé-galinha. As plantas C4 (maioria das gramineas) apresentam altas taxas fotossintéticas e, quando em mesmo nível de luminosidade, são três a quatro vezes mais eficientes na produção de assimilados do que as plantas C3 (Taiz \& Zeiger, 2002). Contudo, em situações na qual a disponibilidade de água se encontra limitada, as plantas poderão sofrer alterações em processos fisiológicos e, assim, alterar o comportamento de indicadores fisiológicos ligados diretamente à fotossintese.

Quanto ao controle químico, ressalta-se que as elevadas perdas de produtividade ligadas à interferência das plantas daninhas, assim como a inexistência de alternativas de igual eficácia, fazem dos herbicidas uma prática essencial e generalizada (Sanino \& Gianfreda, 2001).

Plantas daninhas gramíneas perenes e anuais são comumente controladas, em condições de pós-emergência, com os herbicidas inibidores da ACCase (acetil Co-A carboxilase). Segundo Rodrigues (1994), o modo de ação primário desses herbicidas consiste na inibição da sintese de ácidos graxos, ao inibirem a enzima acetil coenzima-A carboxilase (ACCase). Essa enzima regula uma reação-chave no início da biossíntese de lipídeos necessária para sintese e manutenção de membranas, e não na produção de aminoácidos (converte o acetil coenzima-A em malonil coenzima-A). A ACCase presente em gramíneas é, geralmente, sensivel à inibição por esses herbicidas.

Entretanto, algumas condições são recomendadas para que os herbicidas (pós-emergentes) possam alcançar maior eficiência, como, por exemplo, a aplicação nos momentos em que as plantas apresentam elevada atividade metabólica. Alguns tipos de estresse, como a restrição hídrica, podem causar reação de engrossamento da cutícula das folhas e interferir na absorção dos herbicidas.

O déficit hídrico afeta a bioquímica, a fisiologia, a morfologia e os processos de desenvolvimento das plantas, reduzindo a fotossintese por meio de redução na área foliar disponivel para interceptar a radiação solar; redução da difusão do $\mathrm{CO}_{2}$ para dentro da folha devido ao fechamento dos estômatos; redução da habilidade dos cloroplastos para fixar o $\mathrm{CO}_{2}$ que neles penetra; e enrolamento e senescência das folhas (Levitt, 1980; Jones, 1985; Faver et al., 1996). Esses fatores podem influenciar a eficiência dos herbicidas.

O objetivo deste estudo foi analisar o efeito do potencial de água no solo sobre a eficácia de herbicidas inibidores da enzima acetil coenzima-A carboxilase (ACCase) aplicados em pós-emergência em plantas de $E$. indica submetidas a diferentes estresses hídricos.

\section{MATERIAL E MÉTODOS}

O experimento foi instalado e conduzido no Departamento de Produção Vegetal, Setor Agricultura, da Faculdade de Ciências Agronômicas, UNESP, no município de Botucatu - São Paulo, cujas coordenadas geográficas são: $22^{\circ} 51^{\prime} 03^{\prime \prime}$ de latitude sul e $48^{\circ} 25^{\prime} 37^{\prime \prime}$ de longitude oeste de Greenwich, com altitude de $786 \mathrm{~m}$.

O estudo foi instalado nos meses de fevereiro a abril de 2009, com as seguintes caracterizações climáticas nesse período dentro da casa de vegetação (média): temperatura mínima de $19,3^{\circ} \mathrm{C}$, temperatura máxima de $28,9{ }^{\circ} \mathrm{C}$, umidade relativa do ar de $75,8 \%$ e evapotranspiração de $3,1 \mathrm{~mm}$ mês ${ }^{-1}$, a qual foi monitorada diariamente através de um Tanque Classe A.

A espécie utilizada foi $E$. indica, cultivadas em vasos plásticos de $2 \mathrm{~L}$ contendo solo de descrição textural classificada como média por meio da análise granulométrica $(65,6 \%$ de areia, 6,7 de silte e 27,7 de argila). Foi realizada adubação do solo de acordo com análise química 
(Tabela 1). O solo foi previamente irrigado até que a umidade atingisse a capacidade de campo, de forma a garantir a efetivação do processo de germinação e o desenvolvimento das plântulas. Após a emergência das plântulas foi efetuado um desbaste, deixando duas plântulas por vaso.

O solo, antes da semeadura, foi seco ao ar e revolvido duas vezes por semana até umidade constante de 3\%. Para obtenção da curva de retenção de água, foi utilizada a placa de pressão de Richards (Klar, 1984). A partir dos resultados da curva de retenção, foram estabelecidos três potenciais mínimos de água $(\Psi \mathbf{s})$ : $-0,03,-0,07$ e - 1,5 MPa, sendo 13,10 e $8 \%$ de umidade do solo, respectivamente, compondo os manejos hídricos, avaliados por meio de pesagem dos vasos. Ao atingir as imediações do potencial definido para cada tratamento, foi feita reposição da água evapotranspirada até alcançar a massa do potencial de água máximo de retenção de água do solo (-0,01 MPa, equivalente a $14 \%$ de umidade do solo). Os manejos hídricos foram iniciados no estádio de desenvolvimento de duas folhas em cada planta.

Foi utilizado um pulverizador costal, equipado com barra de aplicação contendo quatro pontas de pulverização tipo jato plano XR11002VS, com consumo de calda de 200 L ha $^{1}$.

A aplicação dos herbicidas foi realizada na fase de desenvolvimento de 4-6 folhas das plantas daninhas. Foram aplicados três diferentes herbicidas (fluazifop-p-butil, haloxyfopmethyl e sethoxydim + óleo mineral Assist), em delineamento experimental, para cada produto, inteiramente casualizado, com quatro repetições, constituído de um fatorial $3 \times 4$, sendo a combinação dos três manejos hídricos $(-0,03,-0,07$ e $-1,5 \mathrm{MPa})$ e quatro doses desses produtos $(100,50,25$ e $0 \%$ da dose recomendada). De acordo com os fabricantes de cada produto, $100 \%$ da dose recomendada de cada herbicida, expressa em gramas de ingrediente ativo por hectare, é de (g i.a. ha-1): sethoxydim: 184; haloxyfop-methyl: 60; e fluazifop-p-butil: 125.

As características fisiológicas avaliadas, como a taxa fotossintética, condutância estomática, transpiração e temperatura da folha, foram medidas com um analisador de gases de infravermelho (IRGA Li-6400 Licor). As avaliações foram realizadas entre $8 \mathrm{e}$ 10 horas da manhã, nas plantas nos diferentes manejos hídricos, sem a aplicação dos herbicidas.

Os efeitos dos tratamentos sobre as plantas foram avaliados visualmente aos 14 dias após aplicação, por meio de uma escala percentual de notas, na qual 0 consiste em ausência de injúria e 100, em morte das plantas (SBCPD, 1995). Ao final das avaliações, as plantas foram coletadas e secas em estufa de ventilação forçada de ar a $60^{\circ} \mathrm{C}$ até atingirem peso constante; em seguida, foi determinada a massa seca das amostras.

Os resultados dos parâmetros fisiológicos e de fitointoxicação foram submetidos à análise de variância pelo teste $\mathrm{F}$, e as massas secas de plantas foram submetidas aos modelos de regressão linear e polinomial, sendo as médias dos tratamentos comparadas pelo teste de Tukey a $5 \%$.

\section{RESULTADOS E DISCUSSÃO}

Aos 14 DAA, nas aplicações de 100\% da dose dos produtos, observaram-se resultados satisfatórios com os herbicidas fluazifop-p-butil e haloxyfop-methyl, sendo acima de 90\%, independentemente do manejo hídrico ao qual as plantas foram submetidas (Tabelas 2 e 3 ). Quanto ao herbicida sethoxydim (Tabela 4), verificaram-se melhores resultados de

Tabela 1 - Análise química do solo utilizado no estudo. Botucatu-SP, 2009

\begin{tabular}{|c|c|c|c|c|c|c|c|c|c|}
\hline $\mathrm{pH}$ & $\mathrm{MO}$ & $\mathrm{P}$ resina & $\mathrm{H}+\mathrm{Al}$ & $\mathrm{K}$ & $\mathrm{Ca}$ & $\mathrm{Mg}$ & $\mathrm{SB}$ & $\mathrm{CTC}$ & $\mathrm{V}$ \\
\hline$\left(\mathrm{CaCl}_{2}\right)$ & $\left(\mathrm{g} \mathrm{dm}^{-3}\right)$ & $\left(\mathrm{mg} \mathrm{dm}^{-3}\right)$ & \multicolumn{5}{|c|}{$\left(\mathrm{mmol} \mathrm{dm}^{-3}\right)$} & $(\%)$ \\
\hline 4,6 & 7 & 3 & 22 & 0,2 & 2 & 2 & 4 & 26 & 15 \\
\hline
\end{tabular}


Tabela 2 - Porcentagem de controle em plantas de Eleusine indica no estádio de 4-6 folhas submetidas a diferentes manejos hídricos, 14 dias após aplicação do herbicida fluazifop-pbutil. Botucatu-SP, 2009

\begin{tabular}{|c|c|c|c|c|}
\hline \multirow{2}{*}{$\begin{array}{l}\text { Manejo Hídrico } \\
\text { (MPa) }\end{array}$} & \multicolumn{4}{|c|}{$\%$ da dose de herbicida } \\
\hline & 0 & 25 & 50 & 100 \\
\hline$-0,03$ & 0,00 a B & 82,00 a $\mathrm{A}$ & 87,00 a $\mathrm{A}$ & 95,00 a A \\
\hline$-0,07$ & $0,00 \mathrm{a} \mathrm{C}$ & $67,50 \mathrm{~b} \mathrm{~B}$ & $86,25 \mathrm{a} A$ & $92,50 \mathrm{a} \mathrm{A}$ \\
\hline$-1,5$ & $0,00 \mathrm{a} \mathrm{C}$ & $67,50 \mathrm{~b} \mathrm{~B}$ & 90,75 a A & $92,00 \mathrm{a} \mathrm{A}$ \\
\hline $\mathrm{F}_{\text {Manejo Hidrico }}(\mathrm{M})$ & \multicolumn{4}{|c|}{$1,556^{\mathrm{ns}}$} \\
\hline $\mathrm{F}_{\text {dose }}(\mathrm{D})$ & \multicolumn{4}{|c|}{$418,936^{* *}$} \\
\hline $\mathrm{F}(\mathrm{M}) \times(\mathrm{D})$ & \multicolumn{4}{|c|}{$1,301^{\text {ns }}$} \\
\hline $\mathrm{CV}(\%)$ & \multicolumn{4}{|c|}{11,5} \\
\hline
\end{tabular}

Médias seguidas de mesma letra, minúscula na coluna e maiúscula na linha, não diferem entre si pelo teste de Tukey $\mathrm{p}>0,05)$. ${ }^{* *}$ - valor significativo pelo teste $\mathrm{F}(\mathrm{p} \leq 0,01)$.

Tabela 3 - Porcentagem de controle em plantas de Eleusine indica no estádio de 4-6 folhas submetidas a diferentes manejos hídricos, 14 dias após aplicação do herbicida haloxyfopmethyl. Botucatu-SP, 2009

\begin{tabular}{|c|c|c|c|c|}
\hline \multirow{2}{*}{$\begin{array}{c}\text { Manejo Hídrico } \\
\text { (MPa) }\end{array}$} & \multicolumn{4}{|c|}{ \% da dose de herbicida } \\
\cline { 2 - 5 } & 0 & 25 & 50 & 100 \\
\hline$-0,03$ & 0,00 a C & 87,50 a B & 95,00 a A & 100,00 a A \\
\hline$-0,07$ & 0,00 a C & $80,50 \mathrm{~b} \mathrm{~B}$ & 94,25 a A & 100,00 a A \\
\hline$-1,5$ & 0,00 a C & 73,75 c B & 94,00 a A & 99,25 a A \\
\hline$F_{\text {Manejo Hidrico (M) }}$ & \multicolumn{4}{|c|}{$6,173^{* *}$} \\
\hline F dose (D) & \multicolumn{4}{|c|}{$2.666,766^{* *}$} \\
\hline F (M) X (D) & \multicolumn{4}{|c|}{$4,483^{* *}$} \\
\hline CV (\%) & \multicolumn{4}{|c|}{4,5} \\
\hline
\end{tabular}

Médias seguidas de mesma letra, minúscula na coluna e maiúscula na linha, não diferem entre si pelo teste de Tukey $\mathrm{p}>0,05)$. ${ }^{* *}$ - valor significativo pelo teste $\mathrm{F}(\mathrm{p} \leq 0,01)$.

Tabela 4 - Porcentagem de controle em plantas de Eleusine indica no estádio de 4-6 folhas submetidas a diferentes manejos hídricos, 14 dias após aplicação do herbicida sethoxydim. Botucatu-SP, 2009

\begin{tabular}{|c|c|c|c|c|}
\hline \multirow{2}{*}{$\begin{array}{c}\text { Manejo Hídrico } \\
\text { (MPa) }\end{array}$} & \multicolumn{4}{|c|}{$\%$ da dose de herbicida } \\
\cline { 2 - 5 } & 0 & 25 & 50 & 100 \\
\hline$-0,03$ & $0,00 \mathrm{a} \mathrm{C}$ & $81,00 \mathrm{a} \mathrm{B}$ & $84,25 \mathrm{a} \mathrm{B}$ & $96,50 \mathrm{a} \mathrm{A}$ \\
\hline$-0,07$ & $0,00 \mathrm{a} \mathrm{D}$ & $46,25 \mathrm{~b} \mathrm{C}$ & $73,75 \mathrm{~b} \mathrm{~B}$ & $85,50 \mathrm{~b} \mathrm{~A}$ \\
\hline$-1,5$ & $0,00 \mathrm{a} \mathrm{D}$ & $23,50 \mathrm{c} \mathrm{C}$ & $55,00 \mathrm{c} \mathrm{B}$ & $74,25 \mathrm{c} \mathrm{A}$ \\
\hline $\mathrm{F}_{\text {Manejo Hidrico(M) }}$ & \multicolumn{4}{|c|}{$163,556^{* *}$} \\
\hline $\mathrm{F}_{\text {dose }}(\mathrm{D})$ & \multicolumn{4}{|c}{$921,312^{* *}$} \\
\hline $\mathrm{F}$ (M) $\mathrm{x}(\mathrm{D})$ & \multicolumn{4}{|c|}{$32,226^{* *}$} \\
\hline $\mathrm{CV}(\%)$ & \multicolumn{4}{|c|}{8,3} \\
\hline
\end{tabular}

Médias seguidas de mesma letra, minúscula na coluna e maiúscula na linha, não diferem entre si pelo teste de Tukey $\mathrm{p}>0,05$ ). ** - valor significativo pelo teste $\mathrm{F}(\mathrm{p} \leq 0,01)$. controle com manejo hídrico de -0,03 MPa, atingindo também niveis acima de 90,0\%. Contudo, a restrição hídrica nas plantas influenciou negativamente, reduzindo as porcentagens de controle para 85, 50 e 74,25\%, em plantas mantidas em solos com tensões minimas de $-0,07$ e -1,5 MPa, respectivamente.

A redução da dose dos herbicidas haloxyfop -methyl e fluazifop-p-butil em 50\% não diminuiu sua eficácia, independentemente do manejo hídrico imposto às plantas, sendo estatisticamente igual à aplicação de 100\% da dose recomendada, como também não ocorreram diferenças entre essas doses reduzidas.

O mesmo não aconteceu com as aplicações do herbicida sethoxydim: houve diminuição de controle em relação à aplicação de 100\% da dose, sendo essa redução de 8,40, 13,70 e $25,9 \%$, nas plantas mantidas em tensões mínimas de -0,03, -0,07 e -1,5 MPa de água no solo, respectivamente. Analisando as porcentagens de controle resultantes da aplicação de meia dose de todos os três herbicidas, verificou-se que não houve diferenças entre as plantas sem estresse hídrico. Já em plantas submetidas a manejos hídricos no solo de -0,07 e -1,5 MPa, notou-se redução em média de 18,3 e 40,5\%, respectivamente, com a aplicação do herbicida sethoxydim, em comparação com os valores de controle dos outros herbicidas.

Todos os herbicidas tiveram seus efeitos reduzidos com a aplicação de um quarto da dose recomendada nas plantas, em todos os manejos hídricos. As maiores porcentagens de controle foram observadas nas plantas sem restrição hídrica (manejo hídrico de -0,03 $\mathrm{MPa}$ ), em que todos os herbicidas atingiram valores acima de $80 \%$ de controle; contudo, verificou-se redução de 11,0 a $14,0 \%$ na fitotoxicidade em relação aos efeitos provocados pela aplicação de $100 \%$ da dose.

Com o aumento da restrição hídrica, incrementou-se a redução de controle com a aplicação de $25 \%$ da dose dos herbicidas, sendo em média de 20 a 45\% em plantas submetidas a manejo hídrico de $10 \%$ e de 24 a $68 \%$ em plantas submetidas a manejo hidrico de -1,5 MPa. Comparando o efeito entre os herbicidas com mesma dosagem (25\%), verificouse que não houve diferenças nas aplicações em plantas sem estresse hídrico. Contudo, nas 
plantas com manejo hídrico de -0,07 $\mathrm{MPa}$, os melhores resultados foram observados com a aplicação do herbicida haloxyfop-methyl $(80,5 \%)$, sendo até $42,5 \%$ mais eficiente que os outros herbicidas. Os efeitos observados nas plantas com manejo hídrico de $-1,5 \mathrm{MPa}$ não se diferenciam com as aplicações dos herbicidas haloxyfop-methyl e fluazifop-p-butil, e o controle destes foi, em média, 66\% melhor controle do que o de sethoxydim.

As plantas sem aplicação de herbicidas, submetidas a solo com umidade de $13 \%$, obtiveram os melhores resultados de massa seca (Figura 1). Observou-se redução de 40 e 62\% quando comparado com a massa de plantas submetidas a manejo hídrico de 10 e $8 \%$, respectivamente. Esse resultado pode ser um dos fatores responsáveis pela maior toxicidade observada em plantas sem restrição hídrica, devido, por exemplo, à maior área foliar, que pode ter proporcionado maior contato dos produtos com elas. Os resultados obtidos por Herrero \& Johnson (1981), em estudos com milho, corroboram os aqui registrados. Esses pesquisadores demonstraram que em condições de déficit hídrico há acentuado declínio na expansão das folhas, que influencia no enrolamento destas e na redução da elongação.

Com a aplicação de $100 \%$ da dose de todos os herbicidas, verificaram-se as maiores reduções de massa seca, em comparação com as plantas sem aplicação dos produtos, independentemente do manejo hídrico utilizado. Com as aplicações do herbicida fluazifop-pbutil, não se observaram diferenças entre as reduções de massa seca de plantas nos diferentes manejos hídricos: na aplicação de 100\% da dose recomendada a diminuição foi em média de $87 \%$, e com a aplicação de $50 \%$ da dose, em média de $78 \%$. Entretanto, com a aplicação de $25 \%$ da dose desse herbicida, a redução da massa seca das plantas submetidas a manejo hídrico de $13 \%$ foi de $34,5 \%$, valor este menor que a média das reduções de massa seca das plantas submetidas aos manejos de 10 e $8 \%$, que foi de $71 \%$.

Comportamento semelhante foi observado com a aplicação do herbicida haloxyfop-methyl, em que as maiores reduções de massa seca $(90 \%)$ foram verificadas em plantas com manejo hídrico de $13 \%$ com aplicação de $100 \%$ da dose recomendada do herbicida. Nota-se pequena queda na redução de massa seca de plantas, conforme se diminuiu a disponibilidade de água, sendo de 86,6 e 84,0\%, em plantas submetidas a manejos hídricos de 10 e $8 \%$, respectivamente.

Com a redução da dose aplicada em 50\%, a diferença da massa seca das plantas sem aplicação do herbicida diminuiu, sendo de $83,6 \%$ nas plantas sem restrição hídrica, e, entre as plantas submetidas a manejos hídricos de 10 e $8 \%$ não houve diferenças entre elas, sendo a redução de 77,6\% na massa seca.

Observaram-se menores reduções de massa seca com a aplicação de um quarto da dose do herbicida haloxyfop-methyl, permanecendo maior para as plantas sem estresse hídrico
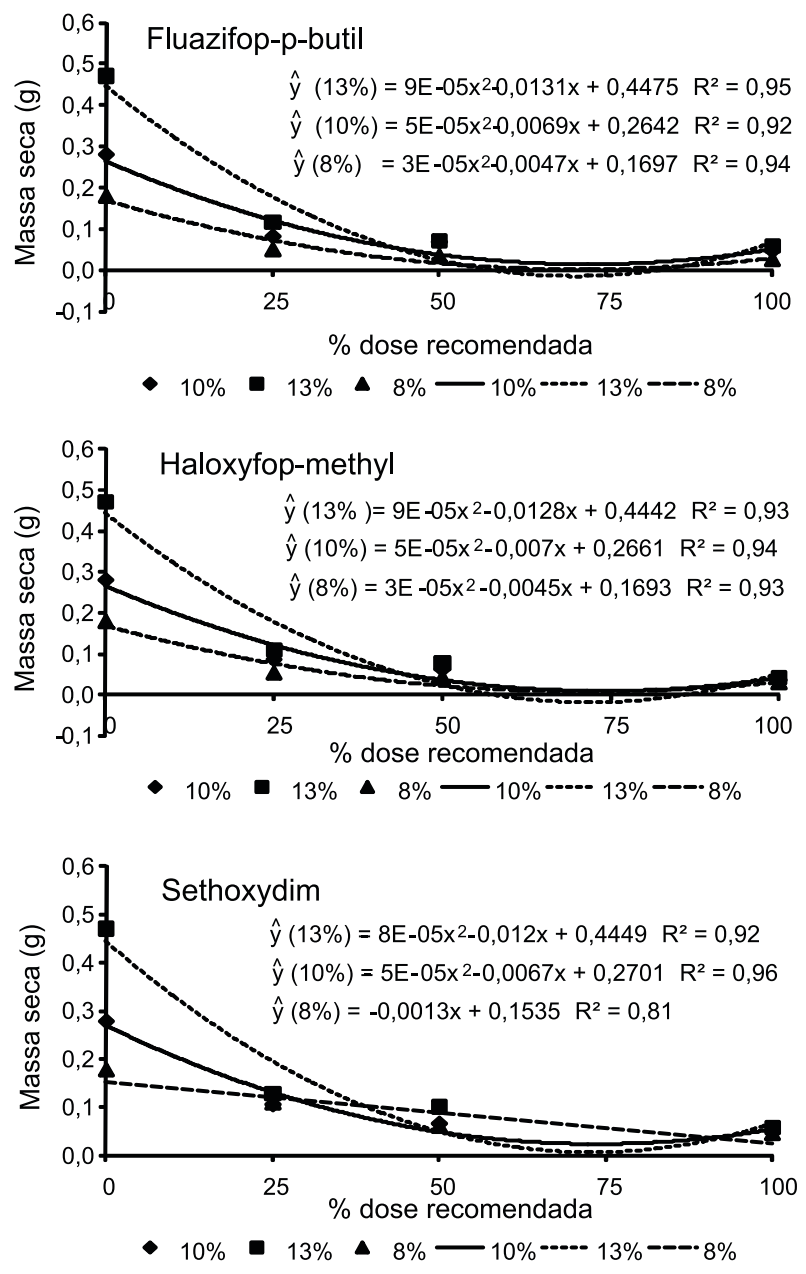

Figura 1 - Massa seca de plantas de E. indica submetidas a diferentes manejos hídricos com aplicação de herbicidas, em quatro doses distintas. Botucatu-SP. 2009. 
(manejo hídrico de 13\%), que foi de $76,8 \%$, e de 68,9 e $70,7 \%$ nas massas secas das plantas submetidas ao manejo hídrico de 10 e $8 \%$, respectivamente.

As reduções nas massas secas das plantas com a aplicação de 100 e 50\% da dose recomendada do herbicida sethoxydim seguiram o mesmo comportamento demonstrado nas outras aplicações. Verificou-se redução de $87,5 \%$ na massa seca de plantas sem estresse hídrico (manejo hídrico de $13 \%$ ) e de 80,5 e $75,0 \%$ na massa seca de plantas com manejos hídricos de 10 e $8 \%$, respectivamente, com a aplicação de $100 \%$ da dose desse herbicida. Essa redução diminuiu conforme houve a redução da dose do herbicida, sendo de 78,6 e $72,8 \%$ a redução da massa seca de plantas (manejo hídrico de $13 \%$ ) submetidas à aplicação de 50 e $25 \%$ da dose do herbicida, respectivamente.

As plantas mantidas em solos com umidade mínima de 10 e $8 \%$ apresentaram reduções na massa seca de 76,0 e 66,5\% (aplicação de meia dose) e 72,8 e 39,0\% (aplicação de um quarto da dose), corroborando os resultados da última avaliação de fitoxicidade, na qual se observou baixa porcentagem de controle nas plantas submetidas a manejo hídrico de $8 \%$ e aplicação de $25 \%$ da dose desste herbicida.

Essa menor redução da massa seca de plantas, mantidas em condições de estresse hídrico com a aplicação dos herbicidas, pode estar relacionada a uma menor absorção e translocação dos produtos, já que, quando as plantas são expostas a situações de déficit hídrico, exibem, frequentemente, respostas fisiológicas, como decréscimo da produção da área foliar, fechamento dos estômatos, aceleração da senescência e da abscisão foliar, bem como enrolamento foliar (McCree \& Fernández, 1989; Taiz \& Zeiger, 2002).

O estresse hídrico pode também produzir efeito no metabolismo das plantas, levando a acúmulo ou perda de metabólitos como carboidratos, ácidos orgânicos, ABA e aminoácidos, além de alterar a atividade de enzimas e sintese de proteinas (Maranville \& Paulsen, 1970). Assim, vários processos fisiológicos, como crescimento de células, síntese de parede, metabolismo de nitrogênio e clorofila, são afetados e, consequentemente, também afetam o acúmulo de massa seca das plantas, bem como podem estar relacionados com a absorção e translocação dos herbicidas.

Vários pesquisadores relacionam a menor massa seca em plantas submetidas a déficit hídrico a processos morfofisiológicos ocasionados pela tentativa de fuga à seca, como demonstrado por Herrero \& Johnson (1981), que trabalharam com milho, e Ball et al. (1994), com algodão; em condições de déficit hídrico pode ocorrer acentuado declínio na expansão das folhas.

Na Tabela 5, observou-se que houve efeito significativo da influência da água na resposta da taxa fotossintética, da transpiração, da condutância estomática e da temperatura foliar nas plantas de $E$. indica sem aplicação dos herbicidas.

As taxas fotossintéticas foram maiores nas plantas mantidas em solo com mínimo de $13 \%$ de umidade, ou seja, sem restrição hídrica, diminuindo gradativamente conforme se reduziu a quantidade de água disponivel a elas. A diferença entre plantas mantidas nessa quantidade de água foi em média de $23 \%$ em relação às mantidas em solo com mínimo de $10 \%$ de umidade, atingindo até um aumento médio de $40 \%$ em comparação com as mantidas em solo com mínimo de umidade de $8 \%$, nos dois estádios avaliados.

Observou-se que o comportamento da transpiração e da condutância estomática acompanhou os resultados da taxa fotossintética, diminuindo de acordo com o grau de restrição hídrica imposto às plantas, nos dois estádios. A transpiração das plantas mantidas em solos com manejos hídricos de 10 e $8 \%$ foi em média de 14 e $27 \%$, respectivamente, menor do que em plantas sem restrição hídrica (manejo hídrico de 13\%). De acordo com Taiz \& Zeiger (2002), a transpiração altera o balanço de energia e o estado hídrico da folha, além da troca de $\mathrm{CO}_{2}$ com o ambiente, fato este que determina o uso e eficiência da água.

A menor disponibilidade de água provocou redução de $34 \%$ na condutância estomática em plantas com manejo hídrico de $10 \%$, atingindo redução de até $53 \%$ nas plantas com manejo hídrico de $8 \%$. A diminuição da 
Tabela 5 - Taxa fotossintética, transpiração, condutância estomática e diferença de temperatura ar-folha em plantas de E. indica mantidas em diferentes umidades do solo. Botucatu-SP, 2009

\begin{tabular}{|c|c|c|c|c|}
\hline Manejo hídrico $(\%)$ & $\begin{array}{c}\text { Taxa Fotossintética } \\
\left(\mu \mathrm{mol} \mathrm{m}{ }^{-2} \mathrm{~s}^{-1}\right)\end{array}$ & $\begin{array}{c}\text { Transpiração } \\
\left(\mathrm{mol}\left(\mathrm{H}_{2} \mathrm{O}\right) \mathrm{m}^{-2} \mathrm{~s}^{-1}\right)\end{array}$ & $\begin{array}{c}\text { Condutância Estomática } \\
\left(\mathrm{mmol} \mathrm{m}^{-2} \mathrm{~s}^{-1}\right)\end{array}$ & $\mathrm{T}$ folha $-\mathrm{T}$ ar $\left({ }^{\circ} \mathrm{C}\right)$ \\
\hline 13 & $28,9 \mathrm{a}$ & $4,00 \mathrm{a}$ & $0,1882 \mathrm{a}$ & $0,54 \mathrm{c}$ \\
\hline 10 & $22,5 \mathrm{~b}$ & $3,39 \mathrm{ab}$ & $0,1305 \mathrm{~b}$ & $2,50 \mathrm{~b}$ \\
\hline $\mathrm{F}_{\text {tratamento }}(\mathrm{T})$ & $17,0 \mathrm{c}$ & $2,84 \mathrm{~b}$ & $0,0930 \mathrm{c}$ & $7,24 \mathrm{a}$ \\
\hline $\mathrm{CV}(\%)$ & $30,311^{* *}$ & $9,498^{* *}$ & $76,762 * *$ & 17,46 \\
\hline d.m.s. & 9,48 & 11,08 & 7,98 & 0,8380 \\
\hline
\end{tabular}

Médias seguidas de mesma letra minúscula, na coluna, não diferem entre si pelo teste de Tukey ( $>0,05)$. **- significativo a $1 \%$.

condutância foliar e transpiração com a restrição hídrica em relação às plantas não estressadas foi similar à encontrada por Kumar \& Tripathi (1990) e Ritchie et al. (1990).

Os manejos hídricos impostos às plantas influenciaram significantemente na temperatura foliar (Tf) destas; os tratamentos com menor disponibilidade de água acarretaram temperaturas foliares maiores do que a temperatura do ambiente (Ta). A diferença entre a Ta e Tf atingiu uma média de $4,0{ }^{\circ} \mathrm{C}$ em plantas submetidas a elevada restrição hídrica (manejo hídrico de 8\%). Essa diferença reduziu gradativamente conforme houve aumento da água disponível para as plantas, sendo em média de $2,4{ }^{\circ} \mathrm{C}$ em plantas mantidas em solos com mínino de $10 \%$ de umidade e de apenas $0,60{ }^{\circ} \mathrm{C}$ nas plantas sem nenhuma restrição de água (mínimo de 13\% de umidade no solo), o que representou redução de mais de $80 \%$ na diferença entre Tar e Tf em relação às submetidas a severo estresse hídrico (manejo hídrico de $8 \%$ ).

Os resultados de fitotoxicidade e os de massa seca observados no presente estudo podem ter sido influenciados pelos parâmetros físiológicos avaliados, devido aos mecanismos de resistência utilizados pelas plantas, que afetam a fotossíntese em situações de déficit hídrico, conforme relataram Lopes et al. (1988).

Nas condições em que o presente trabalho foi realizado, conclui-se que as plantas foram controladas de forma satisfatória pelos herbicidas testados e em todos os manejos hídricos, exceto o herbicida sethoxydim, que foi prejudicado quando da deficiência hídrica. O uso de $50 \%$ da dose recomendada dos herbicidas mostrou-se eficiente em condições controladas de casa de vegetação.

\section{LITERATURA CITADA}

BALL, R. A.; OOSTERHUIS, D. M.; MAUROMOUSTAKOS, A. Growth dynamics of the cotton plant during water-deficit stress. Agron J., v. 86, n. 5, p. 788-795, 1994.

FAVER, K. L. et al. Late season water stress in cotton: Leaf gas exchange and assimilation capacity. Crop Sci., v. 36, p. 922-928, 1996.

FONTES, J. R. A. Conceito, classificação e importância das plantas daninhas. In: FONTES, J. R. A. et al. Manejo integrado de plantas daninhas. Planaltina: Embrapa Cerrados, 2003. p. 8-21. (Documentos, 103).

HERRERO, M. P.; JOHNSON, R. R. Drought stress and its effects on maize reproductive systems. Agron J., v. 21, p. $105-110,1981$.

JONES, C. A. C4 grasses and cereals: growth, development and stress response. New York: John Wiley, 1985. 419 p.

KLAR, A. E. Evapotranspiração. In: KLAR, A. E. A água no sistema solo-planta-atmosfera. 2. ed. São Paulo: Nobel, 1984. $408 \mathrm{p}$.

KUMAR, A.; TRIPATHI, R. P. Relation of leaf-water potencial, diffusice resistance, transpiration rate and canopy temperature in bread wheat (Triticum aestivum). Indian J.

Agric. Sci., v. 60, n. 2, p. 128-131, 1990.

LEVITT, J. Response of plants to environmental stress. II: Water radiation, salt and other stress. New York: Academic Press, 1980. $606 \mathrm{p}$.

Planta Daninha, Viçosa-MG, v. 29, n. 2, p. 397-404, 2011 
LOPES, B. F. et al. Photosynthesis and water vapor exchange of pigeonpea leaves in response to water deficit and recovery. Crop Sci., v. 28, p. 141-145, 1988.

MARANVILLE, J. E.; PAULSEN, G. M. Alteration of carbohydrate composition of corn (Zea mays L.) seedlings during moisture stress. Agron J., v. 62, p. 605-608, 1970.

McCREE, K. J.; FERNÁNDEZ, C. J. Simulation model for studyng physiological water stress responses of whole plants. Crop Sci., v. 29, p. 353-360, 1989.

RITCHIE, S. W. et al. Leaf water content and gas-exchange parameters of two wheat genotypes differing in drought resistance. Crop Sci., v. 30, p. 105-111, 1990
RODRIGUES, J. D. Absorção, translocação e modo de ação de defensivos. Botucatu: UNESP, Instituto de Biociências, 1994. $106 \mathrm{p}$

SANNINO, F.; GIANFREDA, L. Pesticide influence on soil enzymatic activities. Chemosphere, v. 45, p. 417-425, 2001.

SOCIEDADE BRASILEIRA DA CIÊNCIA DAS PLANTAS DANINHAS - SBCPD. Procedimentos para instalação, avaliação e análise de experimentos com herbicidas Londrina: 1995. $42 \mathrm{p}$.

TAIZ, L.; ZEIGER, E. Fisiologia vegetal. 3.ed. São Paulo: Artmed, 2002. 719 p 